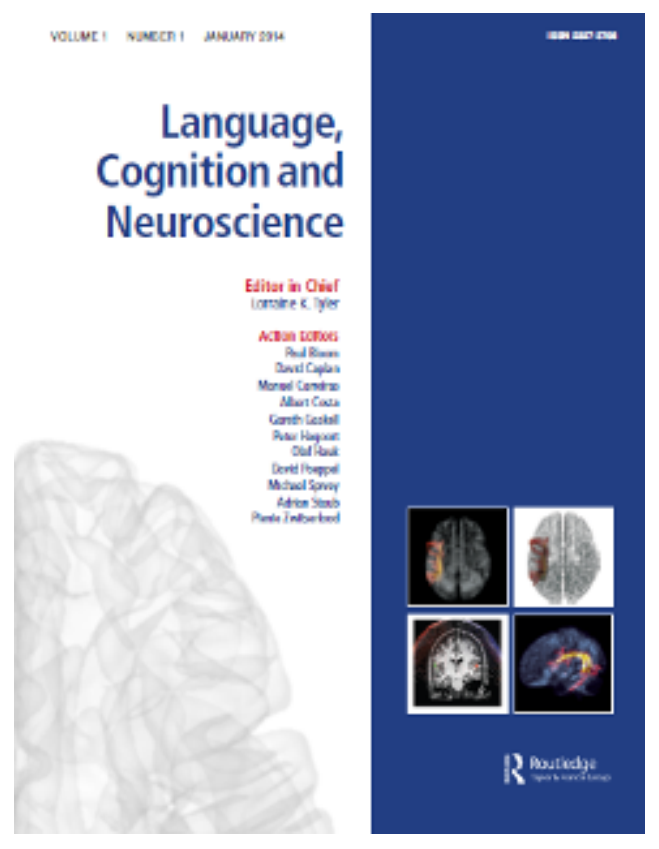

\title{
The Time Course of Speech Production Revisited: No Early Orthographic Effect, Even in Mandarin Chinese
}

\begin{tabular}{|r|l|}
\hline Journal: & Language, Cognition and Neuroscience \\
\hline Manuscript ID & PLCP-2019-OP-10781.R3 \\
\hline Manuscript Type: & Original Paper \\
\hline Author: & n/a \\
\hline Complete List of Authors: & $\begin{array}{l}\text { Wang, Man; Qingdao University, School of Foreign Languages } \\
\text { Chen, Yiya; Leiden University, Linguistics } \\
\text { Jiang, Minghi; Tsinghua University, } \\
\text { Schiller, Niels; University of Leiden, Leiden Institute for Brain and } \\
\text { Cognition, }\end{array}$ \\
\hline Keywords: & $\begin{array}{l}\text { language production, orthography, picture-word interference, Mandarin } \\
\text { Chinese }\end{array}$ \\
\hline &
\end{tabular}

\section{SCHOLARONE \\ Manuscripts}


Running head: THE TIME COURSE OF SPEECH PRODUCTION REVISITED

1

2

3

4 5

6

7

8

9

10
The Time Course of Speech Production Revisited: No Early Orthographic Effect, Even in Mandarin Chinese

Man Wang ${ }^{1,2,3}$, Yiya, Chen ${ }^{2,3}$, Minghu Jiang ${ }^{4} \&$ Niels O. Schiller ${ }^{2,3}$

Author Note

1. School of Foreign Languages, Qingdao University, Qingdao, China

2. Leiden University Center for Linguistics, Leiden, The Netherlands

3. Leiden Institute for Brain and Cognition, Leiden, The Netherlands

4. Center for Psychology and Cognitive Science, Tsinghua University, Beijing, China

Correspondence concerning this article should be addressed to Man Wang, School of Foreign Languages, Qingdao University, Qingdao, Shandong, 266071, China. Phone: +86 13012552107.

Email: emilymanwang@163.com.

This research was supported by the National Natural Science Key Fund (61433015),

China, Shandong Provincial Social Science Planning Research Project (20DYYJ03) and grants from "Talent and Training China-Netherlands" program. 


\section{Abstract}

2 Most psycholinguistic models of speech production agree on an earlier semantic processing 3 stage and a later word-form encoding stage. Using a logographic language, Mandarin Chinese, 4 Zhang and Weekes (2009) reported an early effect of orthography in a picture-word5 interference study and suggested orthography affects speech production via a lexical-semantic 6 pathway at an early stage. This early orthographic effect without co-occurrence of phonological 7 effect, however, was not replicated (Zhao, La Heij, \& Schiller, 2012). The present study aimed

8 to dissociate further the semantic and phonological representations from orthography by using 9 simplex Chinese characters. The results of Experiment 1 and 2 revealed an orthographic effect 10 but only at a similar point in time as the phonological effect, both of which followed the 11 semantic effect. Our results thus raise further doubts about the role of orthography at the 12 conceptual level of speech planning and lend new evidence to a two-step model of speech 13 production.

14 Keywords: language production, orthography, picture-word interference, Mandarin Chinese 
1 The time course of speech production revisited: No early orthographic effect, even in

2

3

4

5

6 Mandarin Chinese

\section{Introduction}

An important issue in psycholinguistic research is the extent to which psycholinguistic models are capable of accounting for cross-linguistic differences. Models of speech production generally recognize several major processing stages: conceptualization, lemma retrieval, wordform encoding and articulation (e.g. Caramazza, 1997; Dell \& O’Seaghdha, 1991, 1992; Levelt, 1989, 1992; the WEAVER++ model, Levelt, Roelofs, \& Meyer, 1999a, b; Roelofs, 1992; Roelofs \& Meyer, 1998). Previous studies have reported that orthographic relatedness modulates the speech production response latencies (Lupker, 1982; Posnansky \& Rayner 1978; Underwood \& Briggs, 1984). It has also been suggested that the orthographic codes are mandatorily activated in speech production based on the evidence that in the form-preparation paradigm (Meyer, 1990), spelling inconsistency of the initial phoneme (e.g., coffee and kennel) interrupts the facilitative effect caused by phonological overlap (e.g., /k/), compared to spelling consistency (e.g., coffee, camel, cushion; Damian \& Bowers, 2003; but see, e.g., Alario, Perre, Castel, \& Ziegler, 2007 as well as Schiller, 2007). However, models of speech production have been mainly based on evidence from West Germanic languages, where orthographic and phonological forms are less clearly distinguished. For instance, the WEAVER++ model postulates a modality-neutral lemma representation where orthography is not specified (Levelt et al., 1999a, b; Roelofs, 1992; Roelofs \& Meyer, 1998). Alternatively, the Independent Network model (Caramazza, 1997; Rapp \& Caramazza, 2002) postulates a modality-specific representation in language production with the semantic representation activating the phonological representation of the lexicon in speech production and orthographic representation in written word production. In other words, the Independent Network model 
1 recognizes the role of the orthographic representation but posits that it only affects written word 2 production.

It is difficult to tease apart orthography and phonology in languages with alphabetic scripts because the correspondence between grapheme and phoneme is relatively transparent, with some showing very consistent mapping (as in Serbo-Croatian) but others relatively less consistent mapping (as in English) (Katz \& Frost, 1992). By contrast, logographic languages show a highly arbitrary grapheme-to-phoneme correspondence. Take Mandarin Chinese as an example; the basic unit of the writing system is a logographic character, and one character usually corresponds to a syllable. The number of possible syllables in Mandarin Chinese is limited, i.e., about 400 syllables excluding lexical tones or about 1,300 syllables including tones (Duanmu, 2002). As a consequence, there is a large number of homophones, with the result that orthography plays a crucial distinguishing role. It is therefore possible that in logographic languages such as Mandarin Chinese orthography plays a different role in speech production compared to languages with alphabetic scripts.

Attempts to address the separate roles of orthography and phonology in speech production have been made in English (Damian \& Bowers, 2009; Lupker, 1982; Posnansky \& Rayner, 1978) using the picture-word interference paradigm (e.g., Lupker, 1979; Rosinski, Golinkoff, \& Kukish, 1975). In this paradigm, participants are asked to name pictures while ignoring superimposed distractor words. It is found that distractor words that belong to the same semantic category as the target interfere with picture naming and phonologically-related distractors facilitate picture naming (e.g., Starreveld, 2000; Starreveld \& La Heij, 1995, 1996; see Glaser, 1992; MacLeod, 1991 for a review of the paradigm). When the distractors are related to the picture name both orthographically and phonologically, the facilitation effect is stronger compared to pure phonological relatedness (e.g., Lupker, 1982; Posnansky \& Rayner 1978; Underwood \& Briggs, 1984). For instance, naming the picture of a chair was faster with 
1 the distractor air $(55 \mathrm{~ms})$ or bear $(23 \mathrm{~ms})$, compared to an unrelated condition, from which the

2 facilitation effect was derived (32 ms) and attributed to orthographic overlap (Lupker, 1982).

3 However, Damian and Bowers (2009) found that 'extra' orthography alone did not modulate

4 the facilitation effect when distractors were presented in the auditory format instead of the

5 visual modality. Therefore, the presence of a pure orthographic effect in speech production has

6 remained unclear.

7 Two factors may have contributed to the discrepancy in the results of the studies based

8 on English stimuli. One factor is the limited number of word pairs that can dissociate 9 orthography and phonology in English (e.g. bear-year). The other factor is that the role of 10 orthography is often not examined independently but rather tested by a subtraction approach 11 (the effect of phonological and orthographic relatedness minus the effect of phonological relatedness; e.g. Lupker, 1982; Posnansky \& Rayner 1978; Underwood \& Briggs, 1984). Damian and Bowers (2009) pointed out that one of the limitations of using English words as stimuli is that the distractors in the orthographically unrelated condition are only orthographically "less similar". Consequently, this might have "underestimated the potential contribution of spelling" (Damian \& Bowers, 2009, p. 595).

Mandarin Chinese provides an ideal testing ground to tease apart the role of orthography and phonology in speech production. As we mentioned earlier, it has a logographic writing system that can help to dissociate phonology and orthography. Each syllable in Mandarin Chinese contains segmental information and a lexical tone, and is represented by a single character that comprises one or more sub-elements, known as 'radicals'. A semantic radical is a sub-element of a Chinese character that conveys semantic information, while a phonetic radical conveys phonological information. For example, 锤 (chui2, 'hammer') (here chui is the alphabetic or 'pinyin' transcription of the Mandarin syllable, and 2 indicates Lexical Tone 2) is a complex character where the left part is a semantic radical 年 indicating that the meaning 
1 denoted by the character is related to metal, and the right part is the phonetic radical 垂 (chui2)

2 suggesting the pronunication of the character 锤 (chui2). Some characters, however, contain

3 only one element (henceforth 'simplex' characters). For example, 羊 (yang2, 'sheep') is a

4 simplex character which cannot be decomposed into sub-parts. Thus, there are Chinese

5 characters which do not provide phonological or semantic information and therefore provide

6 an opportunity to tease apart orthographic, phonological, and semantic information. This

7 provides a great opportunity for us to manipulate the (un)relatedness of orthographic and

8 phonological information. For example, simplex 羊 (yang2, 'sheep') and 央 (yang1, 'center')

9 are only phonologically related (i.e. overlapping at the segmental level yang although differing

10 in lexical tones), while 羊 (yang2, 'sheep') and 半 (ban4, 'half') are orthographically related

11 but have no phonological overlap (i.e. neither in segment nor in tone). None of the characters

12 (i.e., 羊, 央, 半) are related semantically.

Independent orthographic and phonological facilitation effects have been reported in

studies using Mandarin Chinese stimuli (Bi, Xu, \& Caramazza, 2009; Zhang, Chen, Weekes,

\& Yang, 2009; Zhang \& Weekes, 2009; Zhao, La Heij, \& Schiller, 2012). In the picture-word interference paradigm, it is well-established that if the visually presented distractor is semantically related to the target, it exerts an inhibition effect. That is, the semantic representation of the distractor is firstly activated and then inhibits the picture naming process (see, e.g., La Heij, 1988; Levelt et al., 1999a; 1999b; Roelofs, 2003; but see also, e.g., Finkbeiner \& Caramazza, 2006; Finkbeiner, Gollan, \& Caramazza, 2006; Mahon, Costa, Peterson, Vargas, \& Caramazza, 2007; Miozzo \& Caramazza, 2003 for accounts of the semantic effect). If the distractor is phonologically related to the target, however, there would be a facilitation effect. That is, the phonological representation of the target is primed by the distractor (e.g., Perfetti \& Tan, 1998; Zhou \& Marslen-Wilson, 1999a; Zhou, Shu, Bi, \& Shi, 1999) and therefore shortens the naming latency of the target picture. In addition, upon seeing 
1 the distractor, the visual input of the distractor has been reported to activate the orthographic

2 representations of its orthographic neighbors that are visually similar (McClelland \&

3 Rumelhart, 1981, cf. Bi et al., 2009). Such a visual similarity effect has been observed when

4 the distractor is orthographically related to the character of the target picture name. Specifically,

5 the orthographic representation of the target is activated and the activated orthographic code

6 produces a facilitative effect on picture naming, reflected by shorter naming latencies with an

7 orthographically related distractor relative to an unrelated one (Bi et al., 2009; Zhang et al.,

8 2009; Zhang \& Weekes, 2009; Zhao et al., 2012).

The central issue here is when and how the orthographic representation that is activated

by the visual cues in processing the visual words then affects speech production. To tap into

this issue, previous studies have manipulated the stimulus onset asynchrony (SOA) but yielded mixed results regarding the temporal locus of the orthographic effect (Zhang et al., 2009; Zhang \& Weekes, 2009; Zhao et al., 2012). For example, Zhang and colleagues (Zhang et al., 2009; Zhang \& Weekes, 2009) reported orthographic effects with the negative SOAs (-150 ms and $100 \mathrm{~ms}$ ) without co-occurrence of any phonological effect, which led them to claim that sharing orthography might activate the target concept via the lexical-semantic pathway (Link A in

17 Figure 1) and facilitate the target name retrieval at an earlier stage compared to the phonological effect. However, Zhao et al. (2012), failed to replicate the findings in any of the negative SOA conditions (-150 ms in Experiment 1; -150 ms and -75 ms in Experiment 2). Instead, their results demonstrated that orthographically and phonologically related distractors both facilitated picture naming at a similar stage (i.e. with SOA $=0 \mathrm{~ms}$ in Experiment 1 and no interaction between relatedness (two levels: orthographic or phonological) and SOA in Experiment 2). Furthermore, based on the null effect of orthographic relatedness on picture naming and picture categorization in their third experiment, Zhao and colleagues (Zhao et al., 2012) excluded the scenario of orthographic facilitation at the early, conceptual stage. Taken 
1 together, they suggested that the orthographic facilitation effect should be attributed to the

2 word-form encoding stage of speech production.

3

4

5

6

The discrepancy in the findings of Zhao and colleagues (Zhao et al., 2012) and Zhang and colleagues (Zhang et al., 2009; Zhang \& Weekes, 2009) could be attributed to their differences in experimental design. In Zhao et al. (2012), semantic relatedness was not manipulated. In other words, only orthographically (or phonologically) related conditions were compared to orthographically (or phonologically) unrelated conditions. It is possible that orthographic relatedness affects speech production via the interaction with the semantic representation. The experimental design of Zhao et al. (2012), however, does not allow testing this possibility.

\#\# insert Figure 1 about here \#\#

The crucial issue is thus to clarify whether orthography affects speech production by interacting with the semantic representation of the target word. The goal of Experiment 1 of the present study was therefore two-fold. First, we were interested in resolving the controversial empirical findings and planned to to confirm whether orthography affects speech production via a lexical-semantic pathway independent of the phonological effect. Second, we were interested in whether orthography affects speech production by interacting with semantics. To this end, we improved the design in Zhao et al. (2012) and employed a full factorial design including all four possible conditions of semantic and orthographic overlap: semantically and orthographically related, semantically related but orthographically unrelated, orthographically related but semantically unrelated, and unrelated. We used the picture-word interference paradigm with SOAs ranging from negative to positive values to cover the process before and after the activation of the target lemma, respectively (see Schriefers et al., 1990; Zhang \& Weekes, 2009; Zhao et al., 2012). A more refined increment (75 ms) was employed (instead of $100 \mathrm{~ms}$ as in Zhang \& Weekes, 2009) to increase the sensitivity of detecting the hypothesized 
1 effects. If orthography facilitates speech production at the conceptual level, as claimed in

2 Zhang and Weekes (2009), we would expect an orthographic effect at negative SOAs, possibly

3 with the same temporal locus as that of the semantic effect (Zhang \& Weekes, 2009) or showing 4 interaction with the semantic effect.

5 As we noted earlier, in Mandarin Chinese, simplex characters and complex characters 6 have distinctive structural properties. So we used complex characters in Experiment 1 to test 7 possible interactions between semantic and orthography, but we designed Experiment 2 with 8 only simplex-character stimuli. The design with simplex characters only is also a novelty of 9 the present study, which promises to help further disentangle orthographic effect from that of 10 semantic and phonological effects. This is because in complex characters (e.g., 猫, maol, 'cat'; 11 see Figure 2), the semantic radical (i.e., the left part of the character; in this case, $犭$ ) may allow 12 activation from orthography to semantics and the phonetic radical (i.e., the right part of the character; in this case, 苗, miao2, 'sprout') may allow activation from orthography to phonology (苗, miao2, and the target 猫, maol have the same rhyme ao). All existing studies, due to the lack of control in their stimuli, could not rule out such activations. In our study, by using only simplex characters, we made sure that there are no such semantic/phonological radicals that may allow activation from orthography to semantics or phonology. In this way, we excluded possible grapheme-to-phoneme route (Link C in Figure 1) and were able to zoom into the orthographic effect as well as semantic and phonological effects on speech production without having to worry about their possible overlaps. The time course of these independent effects can then be more clearly teased apart when we examine the inhibition and facilitation patterns in picture naming.

\section{Experiment 1}

\section{Methods}




\subsection{Participants}

Twenty native Mandarin speakers ( 5 male; average age $=27.4$ years; $\mathrm{SD}=2.41$ years) studying in the Netherlands (within one year after arrival) were paid for their participation. All participants signed a letter of informed consent, had normal or corrected-to-normal vision and none had any language impairments.

\subsection{Materials and design}

Twenty black-and-white line drawings from the International Picture Naming Project (Bates et al., 2003) and Snodgrass and Vanderwart (1980) databases, or drawn similarly, corresponding to complex character names in Mandarin Chinese (either monosyllabic $\mathrm{N}=7$ or disyllabic $\mathrm{N}=13$ ) were selected as target pictures. Each picture was presented with four types of monosyllabic distractors: a) semantically and orthographically related $(\mathrm{S}+\mathrm{O}+) ; \mathrm{b})$ semantically related but orthographically unrelated (S+O-); c) orthographically related but semantically unrelated (S-O+); d) semantically and orthographically unrelated (S-O-). Ten other pictures corresponding to monosyllabic or disyllabic names were selected from the same databases to serve as fillers.

All the distractors were phonologically unrelated to the targets. The distractors in the four conditions were comparable in terms of word frequency, $F(3,76)<1$ (calculated with the $\log$ frequency of words in the SUBTLEX-CH database; Cai \& Brysbaert, 2010) and visual complexity (number of strokes), $F(3,76)=1.655, p>0.05$. Orthographic relatedness was operationalized by overlapping in one radical of the characters (e.g., 猫, maol, 'cat' and 狗, gou3, 'dog' which overlap in the radical $\rtimes$ ). Please note that the one-radical overlap applied to both monosyllabic and disyllabic target words, so the amount of overlap slightly varied within the orthographically-related condition due to limitations in the available stimuli given the other criteria. Fourteen native Mandarin speakers rated the semantic relatedness of word pairs with one distractor word and its corresponding target word on a 1-7 scale, with a higher 
1 score indicating stronger relatedness. The average rating scores per participant were then

2 submitted to Wilcoxon Signed-Rank tests. The rating scores differed significantly between

3 semantically related and unrelated word pairs, $Z=-3.9, p<0.0001$. The semantic relatedness

4 did not differ between $\mathrm{S}+\mathrm{O}+$ and $\mathrm{S}+\mathrm{O}-, Z=-1.9, p>0.05$ or between $\mathrm{S}-\mathrm{O}+$ and $\mathrm{S}-\mathrm{O}-, \mathrm{Z}=-1.4$, $5 \quad p>0.05$.

6 The design included two factors: Distractor Type $(\mathrm{S}+\mathrm{O}+, \mathrm{S}+\mathrm{O}-, \mathrm{S}-\mathrm{O}+, \mathrm{S}-\mathrm{O}-)$ and SOA $7 \quad(-150 \mathrm{~ms},-75 \mathrm{~ms}, 0 \mathrm{~ms}$, and $75 \mathrm{~ms})$. Each participant received 30 pictures $\times 4$ Distractor Types

$8 \times 4$ SOAs $=480$ trials in total in a pseudo-randomized order such that the same picture did not 9 re-occur within three consecutive trials. The trials were blocked by SOA. The sequence of the 10 blocks was counterbalanced across participants.

\subsection{Apparatus and procedure}

Before the experiment, there was a familiarization and practice session. The participants

were first shown all the pictures with their names underneath, and were then asked to name the pictures without their names presented. Incorrect answers were corrected.

Each trial in the experimental sessions consisted of: a fixation $(300 \mathrm{~ms})$; a blank screen (200 ms); the first stimulus which was either the target picture (350 by 350 pixels) or the distractor depending on the SOA (Arial Unicode MS, 48 point size); followed by the second stimulus (again either target picture or distractor). The stimuli lasted until the voice-key was triggered or a $2 \mathrm{~s}$ limit was exceeded, followed by another blank screen (500 ms). There was a self-paced pause between every two blocks.

The stimuli were presented using the software E-prime 2.0 and reaction times were recorded online by a voice-key connected with a PST serial response box. Incorrectly triggered voice-key responses were corrected manually using the program CheckVocal (Protopapas, 2007). Errors were firstly manually coded on-line and then double-checked based on the voice recordings. 
1

2

3

4

5

6

7

8

9

10

11

12

13

14

15

16

17

18

19

20

21

22

23

24

25

\subsection{Statistical analysis}

The statistical analysis was conducted using the 'lmer4' package (Bates, Maechler,

Bolker, \& Walker, 2014) using a mixed effect model structure (see, Janssen, Hernández-

Cabrera, Van der Meij, \& Barber, 2015, for a similar approach). The initial statistical model

was built with three fixed predictors: semantic relatedness, orthographic relatedness and SOA.

The naming latencies showed a skewed distribution and were therefore log-transformed (base

10). The log-transformed naming latencies $(6,107$ data points) were submitted to the mixed-

effects modeling in R (version 3.1.0; R Core Team, 2014) as the dependent variable. We further

entered two-way interactions between distractor type (semantic and orthographic relatedness)

and SOA, two random intercepts (participant and target picture), and the random slopes of fixed predictors by participant. The model failed to converge, so the least variable random slope (the random slope of orthographic relatedness by participant; judged by its lowest variance value in the model summary) was removed. The of semantic relatedness, coefficient estimate -0.026 , SE $-0.009, t-2.90, p=0.004$, indieating

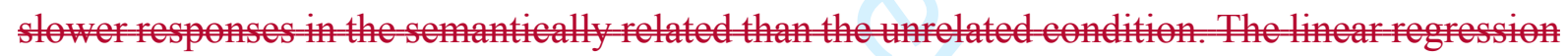
molelalso showed signifieant differences been the reference level (SOA $=150 \mathrm{~ms}$ ) and

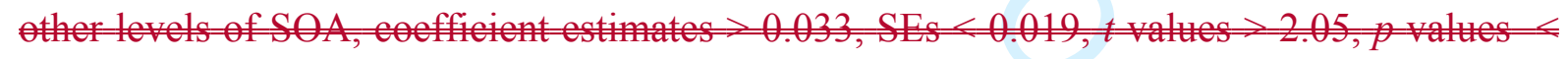
0.05. Since are not interested in the pairwise comparisen of difference SOAs, we did not run further posthoc analyses on the SOA effects. The effect of orthographic relatedness in the initial model did not reach signifieance, coeffieient stimate $=0.007, \mathrm{SE}=0.009, t=0.78, \mathrm{p}=$ 0.435. The interation betwen orthographic relatedness and SOA was signifieant when comparing or thomaphic relatednes at $\mathrm{SOA}-75$ ms to the rerence level (orthographieally

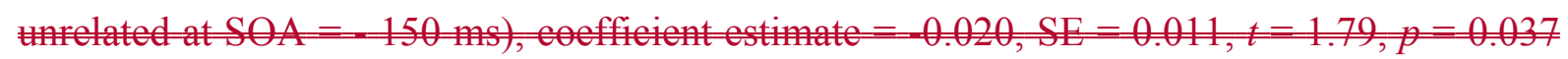
(one al, 2009; Zhang \& Weekes, 2009; Zha at al, 2012).The data were then divided into four subsets per SOA. Separate models were built with semantic 
1 relatedness and orthographic relatedness as the fixed predictors, the random intercepts: the

2 participant and target picture, and the random slopes of fixed predictors by participant. The

3 interaction between semantic relatedness and orthographic relatedness was also tested but

4 model comparisons showed no significance at any SOA (based on the criteria of AIC

5 differences $<2$ and $p$-values $>0.05$ ). Thus, the final models included the fixed effects of

6 semantic relatedness and orthographic relatedness, the random intercepts of participant and

7 target picture, the random slopes of semantic relatedness and orthographic relatedness by 8 participants (Liner mixed model effects syntax:

$9 \operatorname{lmer}(\operatorname{logrt} \sim \mathrm{S}+\mathrm{O}+(1+\mathrm{S} \mid$ Subject $)+(1+\mathrm{O} \mid$ Subject $)+(1 \mid$ Item $)))$. The $p$-values of the final models 10 were obtained using the 'pbkrtest' package (Halekoh \& Højsgaard, 2014).

3. Results and discussion

\#\# insert Table 1 and Figure 3 about here \#\# Errors (3.41\% of all 6,400 data points; including incorrect and disfluent responses) and outliers $(1.17 \%$; shorter than $300 \mathrm{~ms}$ and longer than $1,300 \mathrm{~ms})$ were excluded from further analysis. Error rates were very low and thus considered not informative enough for further statistical analysis. The model-summary of the initial model showed a significant effect of semantic 20 relatedness, eoefficient estimate $\beta=0.026, \mathrm{SE}=0.009, t=2.90, p=0.004$, indicating slower 21 responses in the semantically related than the unrelated condition. The linear regression model 22 also showed significant differences between the reference level ( $\mathrm{SOA}=-150 \mathrm{~ms}$ ) and other 23 levels of SOA, evefficient estimate $\beta \mathrm{S}>0.033$, SEs $<0.019, t$ values $>2.05, p$ values $<0.05$.

24 Since we are not interested in the pairwise comparison of difference SOAs, we did not run 25 further posthoc analyses on the SOA effects. The effect of orthographic relatedness in the initial 
1 model did not reach significance, eoefficient estimate $\beta=0.007, \mathrm{SE}=0.009, t=0.78, p=0.435$.

2 The interaction between orthographic relatedness and SOA was significant when comparing

3 orthographic relatedness at $\mathrm{SOA}=75 \mathrm{~ms}$ to the reference level (orthographically unrelated at

$4 \mathrm{SOA}=-150 \mathrm{~ms}$ ), coefficient estimate $\beta=-0.020, \mathrm{SE}=0.011, t=1.79, p=0.037$ (one-tail;

5 based on Zhang et al., 2009; Zhang \& Weekes, 2009; Zhao et al., 2012).

6

7

8

The final models showed when SOA was $-150 \mathrm{~ms},-75 \mathrm{~ms}$ or $0 \mathrm{~ms}$, there was a significant effect of semantic interference $(+15 \mathrm{~ms},+16 \mathrm{~ms}$ and $+20 \mathrm{~ms}$, respectively; please see Tables 1 and 2). As shown in Figure 3, naming latencies with semantically related distractors were significantly longer than those with semantically unrelated distractors (see, e.g., La Heij, 1988; Levelt et al., 1999a; 1999b; Roelofs, 2003; but see also, e.g. Finkbeiner \& Caramazza, 2006; Finkbeiner, Gollan, \& Caramazza, 2006; Mahon, Costa, Peterson, Vargas, \& Caramazza, 2007; Miozzo \& Caramazza, 2003 for accounts of the semantic effect). There was a significant effect of orthographic facilitation when SOA was $75 \mathrm{~ms}$ (difference of -13 $\mathrm{ms})$. The semantic effect did not reach significance at SOA of $75 \mathrm{~ms}$.

The semantic interference effect was shown at negative SOAs. This result is compatible with previous research using the picture-word interference paradigm in both alphabetic and logographic languages (e.g. Lupker, 1982; Zhang \& Weekes, 2009; Zhang et al., 2009).

Critically, we did not observe an early orthographic effect or any significant interaction between orthographic relatedness and semantic relatedness at negative SOAs. Instead, the orthographic effect was only demonstrated at the positive SOA (i.e., $75 \mathrm{~ms}$, see Tables 1 and 2), suggesting that orthographic relatedness only affected the picture naming process after lemma retrieval, possibly at the word-form processing stage. This result did not confirm the necessity to reconstruct the speech production model regarding the orthographic effect, as suggested by Zhang and Weekes (2009). 
2 temporal loci without any overlap at the specified SOAs (see Figure 3). That is, the semantic

It is worth noting that the significant semantic and orthographic effects have distinctive interference effect was only found at negative SOAs and orthographic facilitation at positive SOAs. This pattern is similar to the pattern of results in Schriefers et al. (1990), suggesting a two-step model of speech production that distinguishes meaning and form processing (but see e.g. Dell, Schwartz, Martin, Saffran, \& Gagnon, 1997 for an interactive two-step model). Furthermore, the magnitudes of the semantic interference and orthographic facilitation was comparable to Zhang and Weekes (2009) but smaller than Zhao et al. (2012). In contrast to Zhang and Weekes (2009), there was only a numerical difference between the orthographically related and the unrelated conditions at negative SOAs (-10 ms at SOA $-75 \mathrm{~ms}$ and $-4 \mathrm{~ms}$ at SOA $0 \mathrm{~ms}$ ). Moreover, the size of the orthographic facilitation effect obtained at SOA $75 \mathrm{~ms}$ was relatively small $(-13 \mathrm{~ms})$ with a $p$-value of 0.035 . There is a possibility that the current design is not sensitive enough to obtain a robust orthographic effect. For instance, the orthographic relatedness represented by sharing one radical (e.g. 碗, wan3, 'bowl' and 矿, kuang4, 'mine' share the radical 石, shi2, 'stone') may not be salient enough to facilitate picture naming. However, increasing evidence has been found to support the decomposition of the Chinese characters involved in reading (e.g., Ding, Peng \& Taft, 2004; Feldman \& Siok, 1999; Qu, Damian, Zhang, \& Zhu, 2011; Zhou \& Marslen-Wilson, 1999b; Yeh \& Li, 2004; but see, e.g., Cheng, 1981; Tzeng, Hung, Cotton, \& Wang, 1979; Yu, Feng, Cao, \& Li, 1990 for a holistic view).

Experiment 2 was therefore designed to tap into the time course of the orthographic effect using simplex characters with orthographic relatedness implemented as overlapping in larger portions (e.g., 兔, tu4, 'rabbit' and 免, mian3, 'exemption'). As explained earlier, in complex characters, the semantic radical or phonetic radical (comprising the orthographic form of the character) usually indicates the semantic category or the phonological form of the 
1 character. Thus, another advantage of using simplex characters is that we can avoid implicit

2 confounding effects of orthography and phonology or semantic information.

3

4

5 4. Methods

6

7

8

9

10

11

12

13

14

15

\section{Experiment 2}

\subsection{Participants}

Sixty-eight native Mandarin speakers (30 male; average age $=21.6$ years; $\mathrm{SD}=2.19$ years) living in Beijing, China were paid for their participation in the experiment. All participants signed a letter of informed consent, had normal or corrected-to-normal vision and none had any language impairments. Following a Latin Square design, there was an increase in sample size in Experiment 2. The sixty-eight native Mandarin speakers were randomly distributed across four groups.

\subsection{Materials and design}

Twenty target pictures were selected from the same sources as in Experiment 1 . The target pictures in Experiment 2 corresponded to monosyllabic simplex names in Mandarin Chinese (i.e. written using non-decomposable, simplex characters). Each picture was presented with four different types of superimposed monosyllabic distractors: a) semantically related but orthographically and phonologically unrelated (S+O-P-); b) orthographically related but semantically and phonologically unrelated (S-O+P-); c) phonologically related but semantically and orthographically unrelated (S-O-P+); d) semantically, orthographically and phonologically unrelated (S-O-P-).

The distractors in the four conditions, as well as the names of the target pictures, were comparable in terms of word frequency, $F(4,95)<1$ (calculated with the log frequency of words in the SUBTLEX-CH database; Cai \& Brysbaert, 2010) and visual complexity (number of strokes), $F(4,95)=1.421, p>.20$. Moreover, two separate online surveys were carried out 
1 to ensure the semantically related distractors were not orthographically related to the targets

2 and vice versa. In each survey, 40 native speakers of Mandarin were asked to rate the semantic

3 or orthographic relatedness of word pairs on a 1-7 scale, with the higher score indicating

4 stronger relatedness. Rating scores were first transformed to z-scores per participant, and then

5 submitted to the Friedman test. There were statistically significant differences in the rating

6 scores for orthographic and semantic relatedness among the four conditions, $\chi^{2}(3)=71.167, p$

$7<0.001$ and $\chi^{2}(3)=67.774, p<0.001$, respectively. Post-hoc analyses using Wilcoxon Signed-

8 Rank tests were conducted with Bonferroni correction. The results showed respectively that

9 orthographically related stimuli were rated as significantly more orthographically related, and

10 semantically related stimuli were rated as significantly more semantically related compared to

11 the other three conditions, $p$-values $<0.001$. Phonological relatedness was represented by

12 overlapping the segmental information of syllable pairs (e.g. 羊, yang, 'sheep' and 央, yang,

13 'center'). Twenty other pictures corresponding to monosyllabic names were selected from the 14 same databases to serve as fillers.

The design included two factors: Distractor Type and SOA $(-150 \mathrm{~ms},-75 \mathrm{~ms}, 0 \mathrm{~ms}$ and $75 \mathrm{~ms}$ ) as in Experiment 1. In total, there were 16 combinations of the two factors. The 16 conditions were assigned to four groups of participants based on the Latin-square method, with 17 participants per group. In this way, each group of participants was presented with four different combinations of distractor type and SOA, and each saw all the pictures, distractor types and SOAs. In total, each participant received 160 trials (4 blocks by 40 trials).

\section{4.3. Apparatus and procedure}

The apparatus and procedure were the same as in Experiment 1.

\subsection{Statistical analysis}

The initial model was built using the 'Imer4' package (Bates et al., 2014) with two fixed 
1 random intercept: target pictures. The naming latencies showed a skewed distribution and were

2 therefore log-transformed. The log-transformed naming latencies (5,253 data points) were

3 submitted to the mixed-effects modelling in $\mathrm{R}$ (version 3.1.0; R Core Team, 2014) as the

4 dependent variable. Since the experiment adopted a between-participants design, the intercept

5 of the participant was correlated with the fixed factors and thus was not entirely random. The

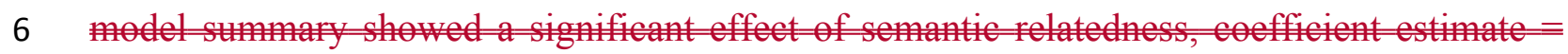

$7 \quad 0.051, \mathrm{SE}=0.015, t-3.35, p<0.001$, indieating slower respenses on semantically related

8 than unmelated trials. The linear regression molelalso sho signicant differences been

9 the reference level (SOA $-150 \mathrm{~ms}$ ) and

10 efficient estimates $>0.045$, SEs $<0.015$, t values $>2.98$, p values $<0.003$. Since are not

11 int in of different sols, did ne

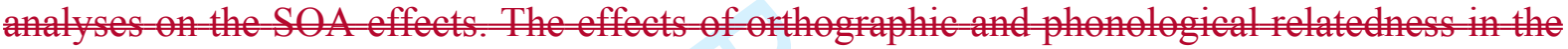

initialmoldid sor

$=0.237$ and coeffieientestimate $-0.008, \mathrm{SE}-0.015, t=0.54, p=0.593$, respectively. The

molel show signifieant interations beendistor and SOA at severallower level

eontrasts, coeffieient estimates $>0.038$, SEs $<0.022$, 1 values $>1.78$, p values $<0.038$ (one-

ail;

then divided into four subsets per SOA. Separate models were built with the distractor type as the fixed predictor and random intercept for target picture (Liner mixed effects model syntax: $\operatorname{lmer}(\operatorname{logrt} \sim$ Distractor $+(1 \mid$ Item $)))$. The adjusted $p$-values were obtained with the Bonferroni method using the 'multcomp' package (Hothorn, Bretz, \& Westfall, 2008).

\section{Results and discussion}

Following the criteria used in Experiment 1, errors (2.61\% of all 5,440 data points; including incorrect and disfluent responses) and outliers $(0.83 \%$; shorter than $300 \mathrm{~ms}$ and 
1 longer than 1,300 ms) were excluded from further analysis. Error rates were very low and thus

2 considered not informative enough for further statistical analysis.

3

4

5 relatedness, eoefficient estimate $\beta=0.051, \mathrm{SE}=0.015, t=3.35, p<0.001$, indicating slower

6 responses on the semantically related than unrelated trials. The linear regression model also

7 showed signicant differences between the reference level ( $\mathrm{SOA}=-150 \mathrm{~ms}$ ) and two other levels

$8 \quad(\mathrm{SOA}=0 \mathrm{~ms}$ and $\mathrm{SOA}=75 \mathrm{~ms})$, coefficient estimate $\beta \mathrm{S}>0.045, \mathrm{SEs}<0.015, t$ values $>2.98$,

$9 p$ values $<0.003$. Since we are not interested in the pairwise comparison of different SOAs, we

10 did not run further posthoc analyses on the SOA effects. The effects of orthographic and

11 phonological relatedness in the initial model did not reach significance, eoefficient estimate $\beta$

$12=-0.018, \mathrm{SE}=0.015, t=-1.18, p=0.237$ and coefficient estimate $\beta=-0.008, \mathrm{SE}=0.015, t=-$

$13 \quad \underline{0.54, p=0.593 \text {, respectively. The model showed significant interactions between distractor }}$

14 type and SOA at several lower level contrasts, eoefficient estimate $\beta \mathrm{s}>0.038$, SEs $<0.022, t$

15 values $>1.78, p$ values $<0.038$ (one-tail; based on Zhang et al., 2009; Zhang \& Weekes, 2009;

16 Zhao et al., 2012).

17 As shown in Table 3 and 4, the final models showed that when SOA was $-150 \mathrm{~ms}$, there

18 was a significant effect of semantic interference ( $+37 \mathrm{~ms})$. Naming latencies with semantically

19 related distractors were significantly longer than those with semantically unrelated distractors

20 (see Figure 4). When SOA was $-75 \mathrm{~ms}$, there was again a significant effect of semantic 21 interference $(+24 \mathrm{~ms})$. The orthographic effect and phonological effect did not reach significance at negative SOAs, $p$-values $>0.05$. These results are in line with the results of

23 Experiment 1. 
1

$2 \mathrm{~ms})$, and a significant effect of phonological facilitation (-26 ms). When SOA was $75 \mathrm{~ms}$, there

3

4

5

6

7

In summary, using solely simplex characters, we did not observe any orthographic effect with negative SOAs, indicating that the early orthographic effect shown in Zhang and Weekes (2009) may not be reliably obtained. Instead, both orthographic and phonological effects were found at positive SOAs, replicating results in Zhao et al. (2012). Furthermore, the magnitudes of orthographic and phonological facilitation were comparable to Zhao et al. (2012), i.e. $37 \mathrm{~ms}$ and $38 \mathrm{~ms}$ after excluding stimuli with phonetic radicals.

\section{General discussion}

Using two experiments, the present study made use of Chinese, a language with logographic scripts, to tease apart the orthographic and phonological representations and test the independent orthographic and phonological effects in spoken word production. The previous literature (e.g., Zhang et al., 2009; Zhang \& Weekes, 2009; Zhao et al., 2012) debated on the time course of the orthographic effect about whether the orthographic relatedness facilitates the conceptual identification of target pictures. Our study revisited this topic and found evidence against this claim. One of the contributions of our study beyond the previous literature is that we tested if there was an interaction between the orthographic representation and semantic representation in picture naming with visual cues, which was not tested in Zhao et al. (2012). Neither an early orthographic effect nor an interaction with semantic relatedness was observed in Experiment 1. One novelty of our study is that we utilized the simplex Chinese characters in Experiment 2 to avoid any semantic and phonetic radicals and to further tease 
1 apart the semantic, phonological and orthographic processing. Again, no early orthographic

2 effect was observed in Experiment 2.

3

4

5

6

7

8

9

In contrast to the results of Experiment 1, at SOA $0 \mathrm{~ms}$, the semantic interference effect did not reach significance in Experiment 2 (see Figure 4). In the previous literature, the presence and absence of semantic effects at $\mathrm{SOA}=0$ have both been reported (e.g., present in Zhao et al., 2012 and absent in Schriefers et al., 1990). One possibility for such discrepancy in our two experiments could be the difference in distractor frequencies between Experiment 1 and 2. The distractor frequency (calculated by taking the $\log$ frequency of words in the SUBTLEX-CH database; Cai \& Brysbaert, 2010) is lower in Experiment 1 (mean = 2.49) than in Experiment $2($ mean $=3.64), p<0.0001$. It has been shown that lower-frequency distractors produce stronger interference at the lexical selection stage (Miozzo \& Caramazza, 2003). The difference in distractor frequency may also explain the faster average naming latencies and lower error rates in Experiment 2 than in Experiment 1, as due to the less interference during lexical selection in Experiment 2. Although Miozzo and Caramazza offered a very plausible explanation for the varying semantic effects in Experiments 1 and 2, we cannot exclude other possibilities that may have contributed to the finding.

Although both the orthographic effect and the phonological effect were significant at the same SOA conditions, we still observed minor differences in their effect sizes. For instance, Experiment 2 revealed that when SOA was $0 \mathrm{~ms}$, the orthographic effect $(p=0.0002)$ was stronger than the phonological effect $(p=0.0307)$, which is in line with previous findings in English (e.g. Lupker, 1982; Posnansky \& Rayner, 1978) and Chinese (Bi et al., 2009). It has been questioned to compare directly the effect sizes of orthographic relatedness and phonological relatedness, partially because the degree of overlap between orthographically related pairs (visual similarity) and phonologically related pairs (differing in tone) hardly allows such a direct comparison (see Bi et al., 2009). Nevertheless, distractors in the current 
1 study were presented visually, and phonological relatedness relies on the activation of the

2 orthographic level (Link B in Figure 1). In other words, orthographic relatedness may play a

3 more critical role when the distractor is presented visually than it does when it is presented

4 auditorily (see, e.g., Damian \& Martin, 1999; Starreveld, 2000), and thus it is not surprising to

5 observe a stronger orthographic than phonological effect.

6 It is worth noting that the distinctive temporal loci of the semantic, orthographic and

7 phonological effects without any overlap in Experiment 2 were similar to the pattern of results

8 found in Experiment 1, which has also been shown for Dutch in Schriefers et al. (1990), where

9 the semantic interference effect was only found at negative SOAs and phonological facilitation

10 at positive SOAs. In both experiments of the present study, the significance of semantic and

11 orthographic effects did not overlap at any SOA. Since both orthographic and phonological

12 effects were significant at $\mathrm{SOA}=0 \mathrm{~ms}$ and $\mathrm{SOA}=75 \mathrm{~ms}$ in Experiment 2, later than when the

semantic effect was observed, what we can conclude is that both orthographic and phonological

effects take place after the conceptual level. This is consistent with the predictions of the

WEAVER++ model in that semantic and word-form processing are localized at disinctive

layers and the activation flows in a discrete manner. Nevertheless, our results do not rule out the possibility that the word form processing level of representation may affect an earlier lexical selection level through feedback connections (Dell \& O'Seaghdha, 1992). Additional research using high temporal resolution measurements such as electrophysiological studies are preferable to settle this debate.

\section{Conclusion}

With two behavioral experiments, the present study shows no early orthographic effect, even in a logographic language like Mandarin Chinese where the orthography is characterized by opaque symbol-to-sound mappings. The results run counter to the proposal that orthography 
1 affects speech production at an early, conceptual level (Zhang \& Weekes, 2009). Rather, the

2 orthographic effects were found at similar temporal loci to the phonological effects, as

3 predicted by most speech production models (e.g. Dell \& O'Seaghdha, 1992; Levelt et al.,

4 1999a, b; Roelofs, 1992; Roelofs \& Meyer, 1998). The results therefore lend further support to

5 a two-step model of speech production in Mandarin Chinese which distinguishes between

6 meaning and form processing.

7

\section{$8 \quad$ 8. Acknowledgement}

9

We thank Elly Dutton for proofreading the manuscript.

10

11

\section{Declaration of interest statement}

The authors declare that the research was conducted in the absence of any commercial

13 or financial relationships that could be construed as a potential conflict of interest. 
2 Alario, F.-X., Perre, L., Castel, C., \& Ziegler, J. C. (2007). The role of orthography in speech 3

4 5 6 production revisited. Cognition, 102, 464-475. http://doi:10.1016/j.cognition.2006.02.002

Baayen, R. H., Davidson, D. J., \& Bates, D. M. (2008). Mixed-effects modeling with crossed random effects for subjects and items._-Journal of Memory and Language,_-59, 390-412. https://doi.org/10.1016/j.jml.2007.12.005

Bates, D., Maechler, M., Bolker, B., \& Walker, S. (2014). lme4: Linear mixed-effects models using Eigen and S4. R package version 1.1-7. This is computer program (R package). The URL of the package is: http://CRAN. R-project. org/package=lme4.

Bates, E., D’Amico, S., Jacobsen, T., Székely, A., Andonova, E., Devescovi, A., ... \& Wicha, N. (2003). Timed picture naming in seven languages. Psychonomic Bulletin \& Review, 10, 344-380. http://dx.doi.org/10.3758/BF03196494

Bi, Y., Xu, Y., \& Caramazza, A. (2009). Orthographic and phonological effects in the pictureword interference paradigm: Evidence from a logographic language. Applied Psycholinguistics, 30, 637-658. https://doi.org/10.1017/S0142716409990051

Cai, Q. \& Brysbaert, M. (2010). SUBTLEX-CH: Chinese word and character frequencies based on film subtitles. PLoS ONE, 5, e10729. https://doi.org/10.1371/journal.pone.0010729

Caramazza, A. (1997). How many levels of processing are there in lexical access? Cognitive Neuropsychology, 14, 177-208. http://dx.doi.org/10.1080/026432997381664

Cheng, C. M. (1981). Perception of Chinese characters. Acta Psychologica Taiwanica, 23, 137-153. http://dx.doi.org/10.1167/8.6.966

Damian, M. F., \& Bowers, J. S. (2003). Effects of orthography on speech production in a formpreparation paradigm. Journal of Memory \& Language, 49, 119-132. https://doi.org/10.1016/S0749-596X(03)00008-1 
1 Damian, M. F., \& Bowers, J. S. (2009). Assessing the role of orthography in speech perception

2 and production: Evidence from picture-word interference tasks. European Journal of Cognitive Psychology, 21, 581-598. http://dx.doi.org/10.1080/09541440801896007

Damian, M. F., \& Martin, R. C. (1999). Semantic and phonological codes interact in single word production. Journal of Experimental Psychology: Learning, Memory, and Cognition, 25, 345-361. https://doi.org/10.1037/0278-7393.25.2.345

Dell, G. S. (1986). A spreading-activation theory of retrieval in sentence production. Psychological Review, 93, 283-321. http://dx.doi.org/10.1037/0033-295X.93.3.283

Dell, G. S. (1988). The retrieval of phonological forms in production: Tests of predictions from a connectionist model. Journal of Memory and Language, 27, 124-142. https://doi.org/10.1016/0749-596X(88)90070-8

Dell, G. S. (1990). Effects of frequency and vocabulary type on phonological speech errors. Language and Cognitive Processes, 313-349. http://dx.doi.org/10.1080/01690969008407066

Dell, G. S., \& O'Seaghdha, P. G. (1991). Mediated and convergent lexical priming in language production: A comment on Levelt et al (1991). Psychological Review, 98, 604614. http://dx.doi.org/10.1037//0033-295X.98.4.604

Dell, G. S., \& O'Seaghdha, P. G. (1992). Stages of lexical access in language production. Cognition, 42, 287-314. https://doi.org/10.1016/0010-0277(92)90046-K

Dell, G. S., Schwartz, M. F., Martin, N., Saffran, E. M., \& Gagnon, D. A. (1997). Lexical access in aphasic and nonaphasic speakers. Psychological Review, 104, 801-838. https://doi.org/10.1037/0033-295X.104.4.801

Ding, G., Peng, D., \& Taft, M. (2004). The nature of the mental representation of radicals in Chinese: A priming study. Journal of Experimental Psychology: Learning, Memory, and Cognition, 30, 530-539. http://dx.doi.org/10.1037/0278-7393.30.2.530 
1 Duanmu, S. (2002). The phonology of Standard Chinese. Oxford: Oxford University Press.

2 Feldman, L. B., \& Siok, W. W. T. (1999). Semantic radicals contribute to the visual

3

4

5

6

7 identification of Chinese characters. Journal of Memory and Language, 40, 559-576. https://doi.org/10.1006/jmla.1998.2629

Finkbeiner, M., \& Caramazza, A. (2006). Now you see it, now you don't: On turning semantic interference into facilitation in a Stroop-like task. Cortex, 42, 790-796. http://dx.doi.org/10.1016/S0010-9452(08)70419-2

Finkbeiner, M., Gollan, T., \& Caramazza, A. (2006). Lexical access in bilingual speakers: What's the (hard) problem? Bilingualism: Language and Cognition, 9, 153-166. https://doi.org/10.1017/S1366728906002501

Glaser, W. R. (1992). Picture naming. Cognition, 42, 61-105. http://dx.doi.org/10.1016/00100277(92)90040-O

Halekoh, U., \& Højsgaard, S. (2014). A kenward-roger approximation and parametric bootstrap methods for tests in linear mixed models - the R package pbkrtest. Journal of Statistical Software, 59, 1-30. http://dx.doi.org/10.18637/jss.v059.i09

Hothorn, T., Bretz, F. \& Westfall, P. (2008). Simultaneous Inference in General Parametric Models. Biometrical Journal, 50, 346-363. http://dx.doi.org/10.1002/bimj.200810425

Janssen, N., Hernández-Cabrera, J. A., Van der Meij, M., \& Barber, H. A. (2015). Tracking the time course of competition during word production: Evidence for a post-retrieval mechanism of conflict resolution. Cerebral Cortex, 25, 2960-2969. https://doi.org/10.1093/cercor/bhu092

Katz, L., \& Frost, R. (1992). The reading process is different for different orthographies: The orthographic depth hypothesis. In R. Frost \& L. Katz (Eds.), Orthography, phonology, morphology and meaning (pp. 67-84). Amsterdam: Elsevier Science Publishers. 
1 La Heij, W. (1988). Components of Stroop-like interference in picture naming. Memory \&

2

3

4

5

6

7

8 Cognition, 16, 400-410. https://doi.org/10.3758/BF03214220

Levelt, W. J. M. (1989). Speaking: From intention to articulation. Cambridge, MA: MIT Press.

Levelt, W. J. M (1992). Accessing words in speech production: Stages, processes and representations. Cognition, 42, 1-22. https://doi.org/10.1016/0010-0277(92)90038-J

Levelt, W. J. M., Roelofs, A., \& Meyer, A. S. (1999a). A theory of lexical access in speech production. Behavioral and Brain Sciences, 22, 1-38. http://dx.doi.org/10.1017/S0140525X99001776

Levelt, W. J. M., Roelofs, A., \& Meyer, A. S. (1999b). Multiple perspectives on word production. Behavioral and Brain Sciences, 22, 61-69. http://dx.doi.org/10.1017/S0140525X99451775

Lupker, S. J. (1979). The semantic nature of response competition in the picture-word interference task. Memory \& Cognition, 7, 485-495. http://dx.doi.org/10.3758/BF03198265

Lupker, S. J. (1982). The role of phonetic and orthographic similarity in picture-word interference. Canadian Journal of Psychology/Revue Canadienne de Psychologie, 36, 349-367. http://dx.doi.org/10.1037/h0080652

MacLeod, C. M. (1991). Half a century of research on the Stroop effect: An integrative review. Psychological Bulletin, 109, 163-203. http://dx.doi.org/10.1037/0033-2909.109.2.163

Mahon, B. Z., Costa, A., Peterson, R., Vargas, K. A., \& Caramazza, A. (2007). Lexical selection is not by competition: A reinterpretation of semantic interference and facilitation effects in the picture-word interference paradigm. Journal of Experimental Psychology: Learning, Memory, and Cognition, 33, 503-535. http://dx.doi.org/10.1037/0278-7393.33.3.503 
1 McClelland, J. L., \& Rumelhart, D. E. (1981). An interactive activation model of context

2

3

4

5

6 effects in letter perception: Part 1. An account of basic findings. Psychological Review, 88, 375-407. http://dx.doi.org/10.1037/0033-295X.88.5.375

Meyer, A. S. (1990). The time course of phonological encoding in language production: The encoding of successive syllables. Journal of Memory and Language, 29, 524-545. https://doi.org/10.1016/0749-596X(90)90050-A

Miozzo, M., \& Caramazza, A. (2003). When more is less: A counterintuitive effect of distractor frequency in picture-word interference paradigm. Journal of Experimental Psychology: General, 132, 228-252. http://dx.doi.org/10.1037/0096-3445.132.2.228

Perfetti, C. A., \& Tan, L. H. (1998). The time course of graphic, phonological, and semantic activation in Chinese character identification. Journal of Experimental Psychology: Learning, Memory, and Cognition, 24, 101-118. http://dx.doi.org/10.1037/02787393.24.1.101

Posnansky, C. J., \& Rayner, K. (1978). Visual vs. phonemic contributions to the importance of the initial letter in word identification. Bulletin of the Psychonomic Society, 11, 188190. https://doi.org/10.3758/BF03336803

Protopapas, A. (2007). CheckVocal: A program to facilitate checking the accuracy and response time of vocal responses from DMDX. Behavior Research Methods 39, 859862. https://doi.org/10.3758/BF03192979

Qu, Q., Damian, M. F., Zhang, Q., \& Zhu, X. (2011). Phonology contributes to writing: evidence from written word production in a nonalphabetic script. Psychological Science, 22, 1107-1112. https://doi.org/10.1177/0956797611417001

Rapp, B., \& Caramazza, A. (2002). Selective difficulties with spoken nouns and written verbs: A single case study. Journal of Neurolinguistics, 15, 373-402. https://doi.org/10.1016/S0911-6044(01)00040-9 
1 Roelofs, A. (1992). A spreading-activation theory of lemma retrieval in speaking. Cognition,

2

3

4

5

6 Roelofs, A., \& Meyer, A. S. (1998). Metrical structure in planning the production of spoken

7

8

9

10

11

12 42, 107-142. http://dx.doi.org/10.1016/0010-0277(92)90041-F

Roelofs, A. (2003). Goal-referenced selection of verbal action: Modeling attentional control in the Stroop task. Psychological Review, 110, 88-125. http://dx.doi.org/10.1037/0033295X.110.1.88 words. Journal of Experimental Psychology: Learning, Memory, and Cognition, 24, 922939. http://dx.doi.org/10.1037/0278-7393.24.4.922

Rosinski, R. R., Golinkoff, R. M., \& Kukish, K. S. (1975). Automatic semantic processing in a picture-word interference task. Child Development, 46, 247-253. http://dx.doi.org/10.2307/1128859

Schiller, N. O. (2007). Phonology and orthography in reading aloud. Psychological Bulletin \& Review, 14, 460-465.

Schriefers, H., Meyer, A. S., \& Levelt, W. J. M. (1990). Exploring the time course of lexical access in language production: Picture-word interference studies. Journal of Memory and Language, 29, 86-102. http://dx.doi.org/10.1016/0749-596X(90)90011-N

Snodgrass, J. G., \& Vanderwart, M. (1980). A standardized set of 260 pictures: norms for name agreement, image agreement, familiarity, and visual complexity. Journal of Experimental Psychology: Human Learning and Memory, 6, 174-215. http://dx.doi.org/10.1037/0278-7393.6.2.174

Starreveld, P. A. (2000). On the interpretation of onsets of auditory context effects in word production. Journal of Memory and Language, 42, 497-525. http://dx.doi.org/10.1006/jmla.1999.2693 
1 Starreveld, P. A., \& La Heij, W. (1995). Semantic interference, orthographic facilitation, and

2 their interaction in naming tasks. Journal of Experimental Psychology: Learning, Memory, and Cognition, 21, 686-698. http://dx.doi.org/10.1037/0278-7393.21.3.686

Starreveld, P. A., \& La Heij, W. (1996). Time-course analysis of semantic and orthographic context effects in picture naming. Journal of Experimental Psychology: Learning, Memory, and Cognition, 22, 896-918. http://dx.doi.org/10.1037/0278-7393.22.4.896

Team, R. C. (2015). R: A language and environment for statistical computing. Vienna, Austria; 2014. URL http://www. R-project. org.

Tzeng, O. J., Hung, D. L., Cotton, B., \& Wang, W. S. Y. (1979). Visual lateralisation effect in reading Chinese characters. Nature, 282, 499-501. http://dx.doi.org/10.1038/282499a0

Underwood, G, \& P, Briggs (1984). The development of word recognition processes. British Journal of Psychology, 75, 243-255. http://dx.doi.org/10.1111/j.20448295.1984.tb01896.x

Yeh, S. L., \& Li, J. L. (2004). Sublexical processing in visual recognition of Chinese characters: Evidence from repetition blindness for subcharacter components. Brain and Language, 88, 47-53. http://dx.doi.org/10.1016/S0093-934X(03)00146-9

Yu, B., Feng, L., Cao, H., \& Li, W. (1990). Visual perception of Chinese characters: Effect of perceptual task and Chinese character attributes. Acta Psychologica Sinica, 22, 141-148,

Zhang, Q., \& Weekes, B. S. (2009). Orthographic facilitation effects on spoken word production: Evidence from Chinese. Language and Cognitive Processes, 24, 1082-1096. http://dx.doi.org/10.1080/01690960802042133

Zhang, Q., Chen, H. C., Weekes, B. S., \& Yang, Y. (2009). Independent effects of orthographic and phonological facilitation on spoken word production in Mandarin. Language and Speech, 52, 113-126. http://dx.doi.org/10.1177/0023830908099885 
1 Zhao, H., La Heij, W., \& Schiller, N. O. (2012). Orthographic and phonological facilitation in 2

7 Zhou, X., \& Marslen-Wilson, W. (1999b). Sublexical processing in reading Chinese. In J. speech production: new evidence from picture naming in Chinese. Acta Psychologica, 139, 272-280. https://doi.org/10.1016/j.actpsy.2011.12.001

Zhou, X., \& Marslen-Wilson, W. (1999a). Phonology, orthography, and semantic activation in reading Chinese. Journal of Memory and Language, 41, 579-606. http://dx.doi.org/10.1006/jmla.1999.2663 Wang, A. Inhoff, \& H.-C. Chen (Eds.), Reading Chinese script: A cognitive analysis (pp. 37-63). Hillsdale, NJ: Erlbaum.

Zhou, X., Shu, H., Bi, Y., \& Shi, D. (1999). Is there phonologically mediated access to lexical semantics in reading Chinese? In J. Wang, A. Inhoff, \& H.-C. Chen (Eds.), Reading Chinese script: A cognitive analysis (pp. 135-171). Hillsdale, NJ: Erlbaum. 
1 Appendix A. Stimuli used in Experiment 1: Target picture names and distractors.

\begin{tabular}{|c|c|c|c|c|}
\hline \multicolumn{5}{|c|}{ Experiment 1} \\
\hline \multirow[b]{3}{*}{$\begin{array}{l}\text { Target } \\
\text { Picture }\end{array}$} & \multicolumn{4}{|c|}{ Distractor type } \\
\hline & \multicolumn{2}{|c|}{ Semantically related } & \multicolumn{2}{|c|}{ Semantically unrelated } \\
\hline & $\begin{array}{l}\text { Orthogra- } \\
\text { phically } \\
\text { related }\end{array}$ & $\begin{array}{l}\text { Orthogra- } \\
\text { phically } \\
\text { unrelated }\end{array}$ & $\begin{array}{l}\text { Orthogra- } \\
\text { phically } \\
\text { related }\end{array}$ & $\begin{array}{l}\text { Orthogra- } \\
\text { phically } \\
\text { unrelated }\end{array}$ \\
\hline 猩猩 & 狮 & 我鸟 & 独 & 柯 \\
\hline xing1xing1 & shil & e2 & $\mathrm{du} 2$ & ke1 \\
\hline gorilla & lion & goose & alone & a name \\
\hline 吉他 & 鼓 & 琴 & 喜 & 知 \\
\hline ji2ta1 & gu3 & qin2 & xi3 & zhil \\
\hline guitar & drum & piano & favor & knowledge \\
\hline $\begin{array}{l}\text { 桌 } \\
\text { zhuo1zi0 } \\
\text { table }\end{array}$ & $\begin{array}{l}\text { 床 } \\
\text { chuang2 } \\
\text { bed }\end{array}$ & $\begin{array}{l}\text { 窗 } \\
\text { chuang1 } \\
\text { window }\end{array}$ & $\begin{array}{l}\text { 杭 } \\
\text { hang2 } \\
\text { a place } \\
\text { name }\end{array}$ & $\begin{array}{l}\text { 答 } \\
\text { da2 } \\
\text { answer }\end{array}$ \\
\hline 梨 & 杏 & 蕉 & 枪 & 缸 \\
\hline li2 & xing4 & jiao1 & qiang1 & gang1 \\
\hline pear & apricot & banana & gun & jar \\
\hline 椅子 & 柜 & 発 & 构 & 硫 \\
\hline yi3zi0 & gui4 & deng4 & gou4 & liu2 \\
\hline chair & closet & stool & structure & sulfur \\
\hline 猫 & 狗 & 鹰 & 犹 & 核 \\
\hline maol & gou3 & ying1 & you2 & he2 \\
\hline cat & $\operatorname{dog}$ & owl & alike & core \\
\hline 碗 & 碟 & 盘 & 矿 & 伯 \\
\hline wan3 & $\operatorname{die} 2$ & pan2 & kuang4 & bo 2 \\
\hline bowl & plate & plate & mine & uncle \\
\hline 胳膊 & 肚 & 头 & 服 & 权 \\
\hline gelbo0 & du4 & tou 2 & fu2 & quan2 \\
\hline arm & belly & head & clothes & power \\
\hline $\begin{array}{l}\text { 腿 } \\
\text { tui3 } \\
\text { leg }\end{array}$ & $\begin{array}{l}\text { 脚 } \\
\text { jiao3 } \\
\text { foot }\end{array}$ & $\begin{array}{l}\text { 手 } \\
\text { shou3 } \\
\text { hand }\end{array}$ & $\begin{array}{l}\text { 朕 } \\
\text { zhen4 } \\
\text { I (used by } \\
\text { the } \\
\text { emperor) }\end{array}$ & $\begin{array}{l}\text { 钢 } \\
\text { gang1 } \\
\text { steel }\end{array}$ \\
\hline 花 & 草 & 叶 & 艺 & 券 \\
\hline hual & cao3 & ye4 & yi4 & quan4 \\
\hline flower & grass & leave & art & coupon \\
\hline 苹果 & 莓 & 桔 & 苍 & 弧 \\
\hline ping2guo3 & mei2 & ju2 & cang1 & hu2 \\
\hline apple & berry & orange & grey & $\operatorname{arc}$ \\
\hline 夢卜 & 葱 & 姜 & 节 & \\
\hline luo 2 boo 0 & cong1 & jiang1 & jie2 & $\begin{array}{l}\text { 尔 } \\
\text { jing1 }\end{array}$ \\
\hline radish & onion & ginger & festival & \\
\hline
\end{tabular}




\begin{tabular}{lllll}
\hline & & & & a place \\
& & & & name \\
\hline 蘑菇 & 菜 & 豆 & 苏 & 库 \\
mo2gu1 & cai4 & dou4 & su1 & ku4 \\
mushroom & vegetable & bean & a name & garage \\
\hline 虾 & 蜂 & 鸡 & 虹 & 福 \\
xia1 & feng1 & ji1 & hong2 & fu2 \\
shrimp & bee & chicken & rainbow & bless \\
蜻蜓 & 蛾 & 豹 & 蚀 & 模 \\
qing1ting2 & e2 & bao4 & shi2 & mo2 \\
dragonfly & moth & leopard & ellipse & model \\
\hline 蝎子 & 蟒 & 鸭 & 褐 & 境 \\
xie1zi0 & mang3 & ya1 & he4 & jing4 \\
scorpion & python & duck & brown & place \\
\hline 钉子 & 锤 & 斧 & 钟 & 件 \\
ding1zi0 & chui2 & fu3 & zhong1 & jian4 \\
nail & hammer & axe & clock & piece \\
\hline 锅 & 铲 & 賣 & 铃 & 地 \\
guo1 & chan3 & hu2 & ling2 & di4 \\
pot & spatula & kettle & bell & ground \\
\hline 饺子 & 饼 & 面 & 馆 & 岛 \\
jiao3zi0 & bing3 & mian4 & guan3 & dao3 \\
dumplings & pastry & noodle & place & island \\
\hline 骆驼 & 驹 & 鲑 & 骗 & 坪 \\
luo4tuo0 & ju1 & gui1 & pian4 & ping2 \\
camel & horse & salmon & lie & grassland \\
\hline & & & &
\end{tabular}


1 Appendix B. Stimuli used in Experiment 2: Target picture names and distractors.

\begin{tabular}{|c|c|c|c|c|}
\hline \multicolumn{5}{|c|}{ Experiment 2} \\
\hline \multirow[b]{2}{*}{$\begin{array}{l}\text { Target } \\
\text { Picture }\end{array}$} & \multicolumn{4}{|c|}{ Distractor type } \\
\hline & $\begin{array}{l}\text { Semanti- } \\
\text { cally } \\
\text { related }\end{array}$ & $\begin{array}{l}\text { Phonologi- } \\
\text { cally related }\end{array}$ & $\begin{array}{l}\text { Orthogra- } \\
\text { phically } \\
\text { related }\end{array}$ & Unrelated \\
\hline 虫 & 龟 & 充 & 史 & 末 \\
\hline chong2 & guil & chong1 & shi3 & mo4 \\
\hline bug & turtle & charge & history & end \\
\hline 勺 & 叉 & 少 & 句 & 川 \\
\hline shao2 & chal & shao3 & ju4 & chuan1 \\
\hline spoon & fork & few & sentence & river \\
\hline 矛 & 盾 & 毛 & 予 & 井 \\
\hline mao2 & dun4 & mao2 & yu3 & jing3 \\
\hline spear & shield & fur & $I$ & well \\
\hline 山 & 谷 & & $凶$ & 瓦 \\
\hline shan1 & gu3 & shan3 & xiong1 & wa3 \\
\hline mountain & valley & blink & bad luck & tile \\
\hline 书 & 本 & 术 & 韦 & 月 \\
\hline shu1 & ben3 & shu4 & we12 & yue4 \\
\hline book & (note)book & skill & $\begin{array}{l}\text { a jamily } \\
\text { name }\end{array}$ & month \\
\hline 牙 & 口 & 亚 & 才 & 日 \\
\hline ya2 & kou3 & ya4 & cai2 & ri4 \\
\hline tooth & mouth & Asia & talent & sun \\
\hline 鱼 & 龙 & 与 & 角 & 七 \\
\hline yu2 & long2 & yu3 & jiao3 & qi1 \\
\hline fish & dragon & and & corner & seven \\
\hline 尺 & 寸 & 赤 & 户 & 辛 \\
\hline chi3 & cun 4 & chi4 & hu4 & xin 1 \\
\hline ruler & inch & red & household & a name \\
\hline 虎 & 牛 & 乎 & 虔 & 巾 \\
\hline hu3 & niu2 & hu1 & qian2 & jin1 \\
\hline tiger & bull & a particle & sincere & towel \\
\hline 耳 & 头 & 儿 & 其 & 久 \\
\hline er3 & tou 2 & er2 & qi2 & jiu3 \\
\hline ear & head & son & its & long \\
\hline 石 & 土 & 式 & 右 & 六 \\
\hline shi2 & tu3 & shi4 & you4 & liu4 \\
\hline stone & sand & pattern & right & six \\
\hline 目 & 鼻 & 母 & 且 & 文 \\
\hline mu4 & bi2 & mu3 & qie3 & wen2 \\
\hline eye & nose & mother & and & text \\
\hline 刀 & 七 & 导 & 力 & r \\
\hline daol & bi3 & dao3 & $1 \mathrm{i} 4$ & bu3 \\
\hline knife & dagger & guide & & \\
\hline
\end{tabular}




\begin{tabular}{|c|c|c|c|c|}
\hline $\begin{array}{l}\text { 风 } \\
\text { feng1 } \\
\text { wind }\end{array}$ & $\begin{array}{l}\text { 雨 } \\
\text { yu3 } \\
\text { rain }\end{array}$ & $\begin{array}{l}\text { 丰 } \\
\text { feng1 } \\
\text { a family name }\end{array}$ & $\begin{array}{l}\text { 冈 } \\
\text { gang1 } \\
\text { hill }\end{array}$ & $\begin{array}{l}\text { 卢 } \\
\text { lu2 } \\
\text { a family } \\
\text { name }\end{array}$ \\
\hline $\begin{array}{l}\text { 人 } \\
\text { ren2 } \\
\text { man }\end{array}$ & $\begin{array}{l}\text { 工 } \\
\text { gong1 } \\
\text { worker }\end{array}$ & $\begin{array}{l}\text { 刃 } \\
\text { ren4 } \\
\text { knife edge }\end{array}$ & $\begin{array}{l}\text { 八 } \\
\text { ba1 } \\
\text { eight }\end{array}$ & $\begin{array}{l}\text { 瓜 } \\
\text { gua1 } \\
\text { melon }\end{array}$ \\
\hline $\begin{array}{l}\text { 手 } \\
\text { shou3 } \\
\text { hand }\end{array}$ & $\begin{array}{l}\text { 足 } \\
\mathrm{zu} 2 \\
\text { foot }\end{array}$ & $\begin{array}{l}\text { 兽 } \\
\text { shou4 } \\
\text { animal }\end{array}$ & $\begin{array}{l}\text { 于 } \\
\text { yu2 } \\
a t\end{array}$ & $\begin{array}{l}巴 \\
\text { ba1 } \\
\text { a name }\end{array}$ \\
\hline $\begin{array}{l}\text { 鼠 } \\
\text { shu3 } \\
\text { mouse }\end{array}$ & $\begin{array}{l}\text { 鸟 } \\
\text { niao3 } \\
\text { bird }\end{array}$ & $\begin{array}{l}\text { 束 } \\
\text { shu4 } \\
\text { bundle }\end{array}$ & $\begin{array}{l}\text { 昆 } \\
\text { kun1 } \\
\text { a name }\end{array}$ & $\begin{array}{l}\text { 币 } \\
\text { bi4 } \\
\text { money }\end{array}$ \\
\hline $\begin{array}{l}\text { 田 } \\
\text { tian2 } \\
\text { farm }\end{array}$ & $\begin{array}{l}\text { 农 } \\
\text { nong2 } \\
\text { agriculture }\end{array}$ & $\begin{array}{l}\text { 天 } \\
\text { tian1 } \\
s k y\end{array}$ & $\begin{array}{l}\text { 甲 } \\
\text { jia3 } \\
\text { first }\end{array}$ & $\begin{array}{l}\text { 气 } \\
\text { qi4 } \\
\text { gas }\end{array}$ \\
\hline $\begin{array}{l}\text { 兔 } \\
\text { tu4 } \\
\text { rabbit }\end{array}$ & $\begin{array}{l}\text { 犬 } \\
\text { quan3 } \\
d o g\end{array}$ & $\begin{array}{l}\text { 凸 } \\
\text { tu1 } \\
\text { convex }\end{array}$ & $\begin{array}{l}\text { 免 } \\
\text { mian3 } \\
\text { exemption }\end{array}$ & $\begin{array}{l}\text { 厂 } \\
\text { chang } 3 \\
\text { factory }\end{array}$ \\
\hline $\begin{array}{l}\text { 羊 } \\
\text { yang2 } \\
\text { sheep }\end{array}$ & $\begin{array}{l}\text { 马 } \\
\text { ma3 } \\
\text { horse } \\
\end{array}$ & $\begin{array}{l}\text { 央 } \\
\text { yang1 } \\
\text { center }\end{array}$ & $\begin{array}{l}\text { 半 } \\
\text { ban4 } \\
\text { half }\end{array}$ & $\begin{array}{l}\text { 五 } \\
\text { wu3 } \\
\text { five }\end{array}$ \\
\hline
\end{tabular}

1 


\section{$1 \quad$ Table 1}

2 The average naming latencies (in $\mathrm{ms}$ ), standard deviations and percentage errors (in

3 parentheses) for each condition in Experiment 1.

\begin{tabular}{lllll}
\hline & SOA $(\mathrm{ms})$ & & \\
\cline { 2 - 5 } Distractor type & -150 & -75 & 0 & 75 \\
\hline Semantically and & & & & \\
orthographically related & $708 \pm 76(2.0)$ & $719 \pm 69(2.2)$ & $744 \pm 71(1.3)$ & $730 \pm 73(2.5)$ \\
Semantically related & $713 \pm 75(2.2)$ & $738 \pm 70(2.0)$ & $749 \pm 83(2.2)$ & $750 \pm 71(3.4)$ \\
Orthographically related & $698 \pm 69(1.7)$ & $712 \pm 61(1.9)$ & $724 \pm 79(2.7)$ & $725 \pm 72(1.6)$ \\
Unrelated & $692 \pm 85(1.9)$ & $713 \pm 62(1.7)$ & $728 \pm 76(3.0)$ & $733 \pm 68(1.9)$ \\
\hline
\end{tabular}

4 
1

2 Table 2

3 The results summary: coefficient estimates, standard errors (SE), $t$-values and $p$-values for the 4 effect of distractor type in each SOA condition in Experiment 1. (significance codes: 0 '***', 50.001 '**’0.01 ‘*’0.05“” 0.1 “” 1)

\begin{tabular}{llrrrl}
\hline SOA (ms) & Distractor Type & Coefficient Estimate & SE & $t$ Value & $p$ Value \\
\hline-150 & Intercept & 6.527 & .029 & 224.347 & \\
& Semantic relatedness & .020 & .008 & 2.597 & $.014^{*}$ \\
& Orthographic relatedness & .002 & .008 & .196 & .846 \\
& & & & & \\
-75 & Intercept & 6.560 & .024 & 275.689 & \\
& Semantic relatedness & .021 & .008 & 2.476 & $.018^{*}$ \\
& Orthographic relatedness & -.014 & .009 & -1.591 & .121 \\
& Intercept & & & & \\
& Semantic relatedness & 6.576 & .028 & 236.362 & \\
& Orthographic relatedness & .026 & .008 & 3.169 & $.003^{* *}$ \\
& & -.010 & .009 & -1.056 & .299 \\
& Intercept & & & & \\
& Semantic relatedness & 6.583 & .026 & 256.912 & \\
& Orthographic relatedness & .016 & .008 & 1.946 & .061 \\
& & -.019 & .009 & -2.208 & $.035^{*}$ \\
\hline
\end{tabular}

6 
1 Table 3

2 The average naming latencies (in $\mathrm{ms}$ ), standard deviations and percentage errors (in

3 parentheses) for each condition in Experiment 2.

\begin{tabular}{lllll}
\hline & \multicolumn{5}{l}{ SOA $(\mathrm{ms})$} & \\
\cline { 2 - 5 } Distractor type & -150 & -75 & 0 & 75 \\
\hline Semantically related & $657 \pm 59(1.5)$ & $656 \pm 60(2.9)$ & $653 \pm 69(2.6)$ & $588 \pm 107(1.3)$ \\
Orthographically related & $610 \pm 55(1.7)$ & $621 \pm 96(0.9)$ & $615 \pm 67(0.9)$ & $528 \pm 79(0.6)$ \\
Phonologically related & $616 \pm 71(0.7)$ & $627 \pm 51(1.1)$ & $627 \pm 66(1.3)$ & $523 \pm 59(1.7)$ \\
Unrelated & $620 \pm 53(0.9)$ & $632 \pm 64(1.3)$ & $653 \pm 71(1.1)$ & $565 \pm 53(1.1)$ \\
\hline
\end{tabular}

4

5 
$1 \quad$ Table 4

2 The results summary: coefficient estimates, standard errors (SE), $t$-values and $p$-values for the

3 effect of distractor type in each SOA condition in Experiment 2. (significance codes: 0 '***' 40.001 '**’ 0.01 '*’0.05 “.” 0.1 “” 1)

\begin{tabular}{llrrrr}
\hline \multirow{2}{*}{ SOA (ms) } & Distractor Type & $\begin{array}{c}\text { Coefficient } \\
\text { Estimate }\end{array}$ & SE & $t$ Value & $p$ Value \\
& & 6.416 & .018 & 350.2 & \\
\hline-150 & Intercept & .051 & .013 & 3.8 & $<.001^{* * *}$ \\
& Semantic relatedness & -.018 & .013 & -1.3 & .537 \\
& Orthographic relatedness & -.008 & .013 & -0.6 & 1.000 \\
& Phonological relatedness & & & & \\
-75 & Intercept & 6.433 & .018 & 352.2 & \\
& Semantic relatedness & .035 & .014 & 2.6 & $0.032^{*}$ \\
& Orthographic relatedness & -.021 & .014 & -1.6 & .351 \\
& Phonological relatedness & -.006 & .014 & -0.4 & 1.000 \\
& Intercept & 6.461 & .018 & 363.0 & \\
& Semantic relatedness & .001 & .014 & -0.1 & 1.000 \\
& Orthographic relatedness & -.056 & .015 & -3.9 & $<0.001^{* * *}$ \\
& Phonological relatedness & -.037 & 0.014 & -2.6 & $0.031^{*}$ \\
& Intercept & & & & \\
& Semantic relatedness & .309 & .022 & 287.64 & .657 \\
& Orthographic relatedness & .024 & .019 & 1.2 & $<0.001^{* * *}$ \\
& Phonological relatedness & -.077 & .019 & -4.1 & $<0.019 * *$ \\
\hline
\end{tabular}

5

6 
Figure 1. The model of overt picture naming with distractors in Chinese (adapted from Bi et al., 2009 and Zhao et al., 2012). Link C was drawn as the grapheme-to-phoneme GPC route and graphed as a dashed line because the sub-lexical GPC route was ruled out in our study. 


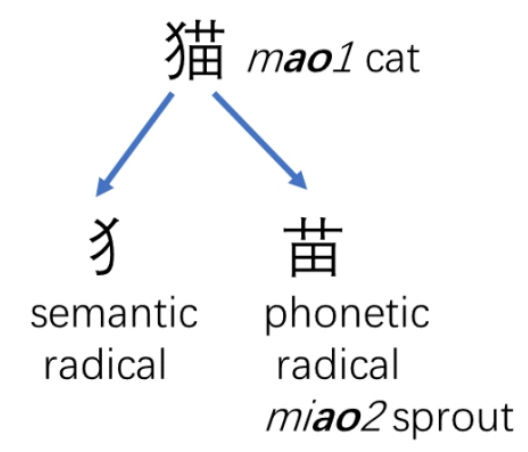

Figure 2. Illustration of an example of complex characters with semantic and phonetic radicals. 


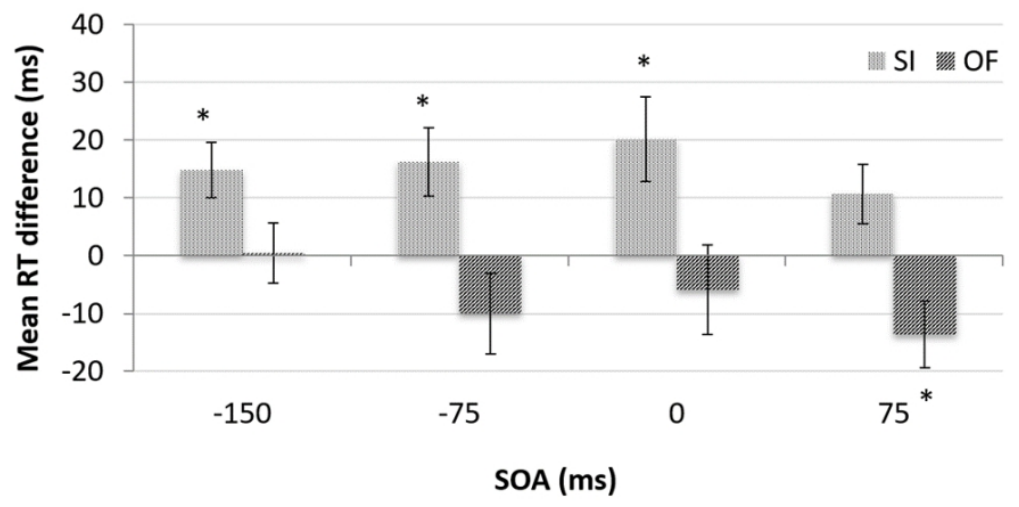

Figure 3. The main effects of semantic and orthographic distractors on picture naming latencies in Experiment 1 shown in reaction time differences across all participants. SI = semantic interference; OF = orthographic facilitation. The error bars represent standard errors of the means. 


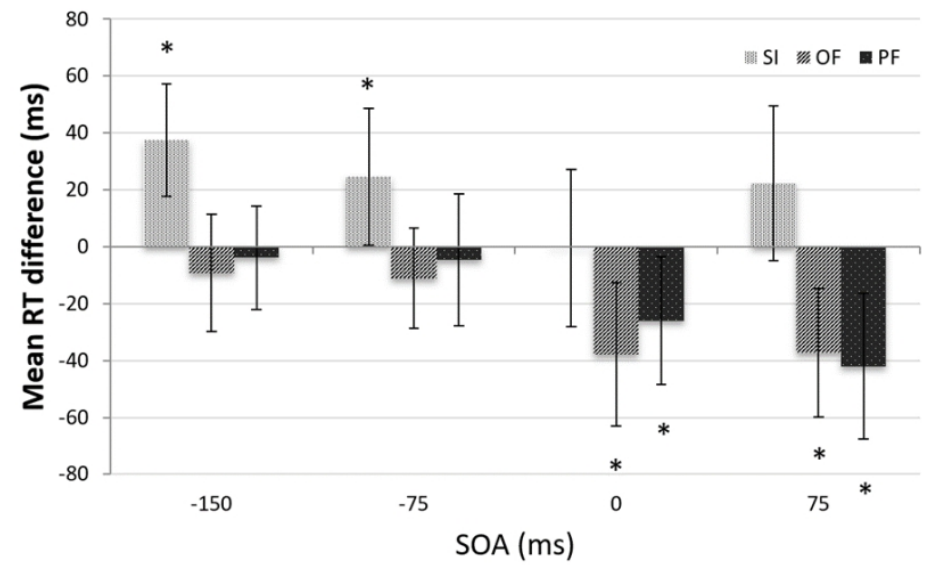

Figure 4. The main effects of semantic, orthographic and phonological distractors on picture naming in Experiment 2 shown in mean reaction time differences across all participants. SI = semantic interference; OF = orthographic facilitation; PF = phonological facilitation. The error bars represent standard errors of the means. 